\title{
TEACHING VOCABULARY IN AVIATION ENGLISH COURSE: A STEP-BY-STEP METHOD, STRATEGIES AND CLASSROOM ACTIVITIES
}

\author{
Yevheniia Tokar ${ }^{1}$, Inna Fainman ${ }^{2}$ \\ Flight Academy of National Aviation University, Kropyvnytskyi, Ukraine \\ E-Mail: ${ }^{1}$ finejenya@hotmail.com, ${ }^{2}$ fineinna@yahoo.com
}

\begin{abstract}
The primary focus of this paper on methodology is the lexical content of systematic and carefully devised course for teaching English to aviation students in order to expand their English vocabulary and, thus, allow them to communicate more freely and clearly. Having a large English vocabulary is a very important part of communication in aviation industry. Along with pronunciation and grammar, it provides the foundation for better speaking and listening skills. The first part of the paper discusses current vocabulary teaching strategies. The second section offers a teaching method of intentional planned work on aviation glossary items, arranged by the authors into a logical consistent workflow with several subsequent stages and steps. We state that mastering a word means complete understanding of its meaning, its use, and its ability to get connected with other words in a sentence. We underline the importance of regular, intentional exercises in practicing vocabulary after it has been presented to students. Thus, we differentiate the following stages in vocabulary teaching course: 1) presentation, which includes. semantization, addressing the word form and working on the word usage/collocation; 2) multiple exposures to targeted words, i.e. practising word recognition and production in a meaningful context (in collocations, phrases, sentences, and on out-of-phrase level - dialogues or monologues); and 3) active involvement in different speech acts. Each part is supplemented with examples of strategies, classroom techniques and exercises to be used in Aviation English course.
\end{abstract}

Key words: Aviation English vocabulary, semantization, providing multiple exposures, active involvement

\section{INTRODUCTION}

Effective, clear and reliable communication between pilot and air traffic controller is a vital element of safe air-traffic navigation (Kolosov, Ivanova, 2000, p. 90). Unfortunately, despite of a huge technological advancement, air accidents have not stopped occurring, though; they have changed their nature and causes. A human factor where the issue of communication takes an important role has been put forward and taken the lead position.

As stated by Bieswanger (2016):

... for several decades aviate - navigate-communicate has been widely known as the axiomatic set of any pilot's duties. (...) The order implies that the primary concern of any flight crew must be to maintain control over the aircraft, the second duty is to make sure that the aircraft moves in the direction it is supposed to fly and the third priority is to communicate the intentions of the flight crew and to receive

Submitted March $26^{\text {th }}, 2018$, accepted for publication September $17^{\text {th }}, 2018$ 
instructions from the air traffic controller. However, this order doesn't mean that communication is not important. (p. 68)

Developing English proficiency when training pilots and air-traffic controllers is significant in contributing to air transportation safety. Language proficiency is not merely knowing vocabulary, grammar rules and norms of pronunciation. It is a complex interaction of a number of skills and abilities, which constitute person's communicative competence (ICAO 2010, p. 2). Lexical competence alongside with pronunciation and structure/grammar provides the foundation for fluency and comprehension skills which are further combined to ensure proficiency in interaction.

Aviation expert demonstrates lexical proficiency in accuracy, range and speed of access to the vocabulary required in the situation. In the professional communication lack of necessary lexical skills leads to miscommunication or interaction breakdown. According to Wang's (2011) research, vocabulary is "a number one obstacle in reading comprehension, followed by grammar and background knowledge; greatest barrier in listening comprehension, followed by speaking speed and accent, greatest impediment to oral and written expression, followed by organizing viewpoint and grammar" (p. 46). It is difficult to have successful communication without knowing grammar or having correct pronunciation, but one can hardly ever do it without appropriate vocabulary skills. Thus, acquiring lexical competence and thorough vocabulary teaching in Aviation English Course is an obvious need.

For a long time one of the dominant ways of teaching vocabulary used to be learning lists of professional vocabulary items, reading and translating texts. Nowadays, with the overall advance around us and the change in the direction of personal and professional ways of development, there has appeared a big need to encourage student's autonomy, develop lexical proficiency as a complex skill set and revise vocabulary teaching methods respectively. Though there have been some publications on distinguishing challenges and methods of aviation vocabulary teaching (Wang, 2011; Secer \& Sahin, 2014), there is still lack of research and methodological papers regarding a systematically elaborated method for explicit vocabulary teaching within Aviation English course.

The general objective of this methodological article is to develop an effectively arranged step-by-step method of teaching vocabulary in Aviation English course, and present vocabulary teaching strategies pertinent to each stage of the method.

\section{TEACHING AVIATION ENGLISH VOCABULARY: LITERATURE REVIEW}

Aviation English Course taught at colleges and universities can generally be regarded as English for Specific Purposes. According to Strevens (1988):

English for Specific Purposes (ESP) is designed to meet specific needs of the learner. ... The language taught to the ESP learners is related in content (themes and topics) to the professional context it is going to be used in. ... Moreover, the language needed in these activities is in the centre of the course, and it covers all the language needed by the learner in order to function in a given work environment. (p. 4) 
ESP traditionally is defined as an "approach to language teaching", rather than a product and in this approach "all decisions as to content and method are based on the learner's reason for learning" (Hutchinson \& Waters, 1987, p. 19). Teaching aviation vocabulary is crucial in Aviation English Course as ESP since the communicators may already have some knowledge of English, they may need a review of their grammar skills, but it is very likely that the lexicon that will appear in their professional field is unknown to them. They may be perfectly fluent in general English, but when it comes to ESP - Aviation English in particular, they may lack this domain specific vocabulary. In such a course of events they will use communicative strategies to avoid using specialized words, which can be disastrous for communication in the aviation field.

Secer \& Sahin (2014), focusing on challenges of teaching aviation vocabulary and radio phraseology at high school level, state the following:

The global aspect of aviation technology resulting in varied cultural and lingual practices in aeronautical industry poses great difficulties for students of aeronautical English, including different lexical forms, semantic features and pronounceability of technical English words. In other words, this multiplicity and variety of aviation communities affects aviation vocabulary learning with regard to the meaning, form, spelling and pronunciation of technical terms. This problematic nature of aviation vocabulary learning makes the teaching of it more important as a subdivision of ESP. (Secer\& Sahin, 2014, pp. 111-112)

We consider paying particular attention to teaching vocabulary, especially devoting a great deal of attention to the issue of its productive use, to be the one of prime importance in pilots' and air traffic controllers' language training. Dudley-Evans \& John (1998) are of the opinion that teaching ESP vocabulary is the same as teaching English for General Purposes. Therefore, general vocabulary teaching approach or method can be applicable in teaching aviation vocabulary as well.

Nation (2001) argues for a systematic, rather than an incidental approach to vocabulary teaching and states that such a focus is an essential part of a language course. Explicit vocabulary teaching can ensure a systematic and logical path alongside with learner's implicit vocabulary acquisition. Smeliakova and Skliarenko (1999) state that the process of intentional teaching vocabulary items has got several stages:

1. Presentation of vocabulary items or their semantization;

2. Automatization of student's actions with lexical units, where there are differentiated:

- automatization on the level of word form, of free expression and phrase;

- automatization on out-of-phrase level - dialogues or monologues.

After that students improve their actions with lexical units and use them in situations while expressing their thoughts orally and in written form and recognize them in context while reading and listening (p. 95).

Seal (1991) offered a three Cs method of teaching vocabulary, which starts from conveying meanings to students by using different classroom techniques. Then the teacher checks the meanings to confirm that students understand what has been conveyed. Finally, the meanings can be consolidated by practising them in contexts (p. 296-311). According to Akbarov (2010), vocabulary teaching and learning is a cycle of semantization and internalization. Semantization is supposed to be the stage of presenting lexical items where 
various strategies (creating meaningful context, teaching words in groups, encouraging guessing, etc.) are used by the teacher. However, it should be followed by the use of lexis in a variety of vocabulary-oriented output activities, since "only through constant consolidation can vocabulary be internalized” (Akbarov, 2010, p. 179).

A word is a complex element. One cannot limit oneself to only knowing the meaning of a word, but must understand how the word is connected with other elements in the process of communication. To master a word means to master its meaning, form (sound and visual images), its ability to get connected with other words (semantic and grammar collocation). Chuksina and Yanovskaya point out that:

... lexical skills which are included into linguistic competence and which are to be acquired in the process of training students at a technical educational establishment (like flight academies, flight schools, etc.) include identification and correct usage of word-formative (affixes and prefixes) elements of lexical units; structural-semantic identification of lexical units within a sentence; adequate and precise usage of general, terminological and scientific vocabulary in oral and written speech. (Chuksina \& Yanovskaya, 2014, p. 3).

In order to develop students' lexical competence a teacher can apply a number of strategies and activities. Hatch \& Brown (2000) state that teaching strategies refer to everything teachers do or should do to help their learners learn (p. 401). The choice of a teaching strategy to be applied depends on the time available, the component of knowledge learners are to acquire, and its value for the learner as well.

A distinction is made between planned and unplanned teaching strategies (Seal, 1991). Unplanned teaching strategies relate to a spontaneous teacher's reaction with the aim to help students when need arises. Planned vocabulary teaching presupposes deliberate, clearly defined, explicit and directed use of teaching strategies, i.e. "ways in which teachers introduce and present the meaning and form of new lexical items, encourage learners to review and practice, i.e. recycle what is known, and monitor and evaluate the level of acquisition of various components of lexical knowledge" (Takač, 2008, p. 19). Planned vocabulary activities are likely to occupy more time than unplanned vocabulary teaching strategies because teachers normally would have prepared teaching materials in advance or have a list of the target words which would have most class teaching time. Takač (2008) divides planned vocabulary teaching strategies into two categories: (1) those used for presentation meaning and form of new lexical items, and (2) those applied for review and consolidation (recycling and practicing) of the presented lexical items (p. 19).

The main issue is that there is always an opportunity of choosing among the broad range of strategies or methods. Teacher can apply a vocabulary instruction or activity, catering for individual learning styles, considering time available or being just pertinent in that context or situation. It is of high importance to encourage students' active participation in vocabulary learning, to support their own lexical discoveries, not to judge which single strategy will be the best for students, but to offer a range of options and activities, and also teach students to educate themselves in order to be able to deal with lexical units outside the classroom. 


\section{BASIC IDEAS FOR THE AVIATION VOCABUlaRy TEACHING METHOD}

Our critical analysis of scholarly publications on vocabulary teaching gave ground to distinguishing basic conceptual ideas, which formed the framework of our vocabulary teaching method in Aviation English course:

1. Vocabulary acquisition cannot rely only on implicit incidental learning. It also requires explicit vocabulary teaching which should stick to a systematically elaborated and effectively arranged workflow of steps.

2. A word is a complex item involving meaning, form, collocations and discourse patterns. When presenting new lexical items, only conveying the meaning is not enough. Word form and collocations require deliberate attention and work.

3. Vocabulary recycling and practice are necessary to consolidate lexis in longterm memory, to stimulate students to retrieve words from it and use them for all language skills.

4. Naturally having a linear and systematic character, vocabulary teaching method does not exclude possible dynamic changes within each stage.

5. A teaching method is not a technological algorithm which must surely lead to a certain predetermined result. Even a well-planned vocabulary teaching method based on contemporary pedagogical principles cannot guarantee every learner to acquire the vocabulary taught, since learning vocabulary through formal instruction is influenced by a number of external factors.

\section{Vocabulary Teaching StageS}

Theoretical framework of the subject and the findings of the research formed the ground for developing our method of teaching vocabulary in Aviation English course.

We differentiate the following vocabulary teaching stages:

1. Presentation which includes:

- Semantization - introducing the meaning of a word;

- addressing the word form - pronunciation and spelling;

- working on the word usage/collocation, i.e. explaining its register/context of usage, how to be used with other parts of speech;

2. Multiple exposures to targeted words - practicing word recognition and production in a meaningful context:

- exposure to targeted vocabulary in collocations, phrases, and sentences;

- developing fluency on out-of-phrase level - dialogues or monologues;

3. Active involvement in different kinds of speech acts.

All the three mentioned stages of work on vocabulary appear to be a unity aimed at developing students' lexical competence and their ability to communicate in the professional aviation context.

\subsection{Presentation}

Presentation is a very significant stage and the effectiveness of its organization is crucial for memorizing words. During this stage students get acquainted with semantics of a new lexical unit, its sound and graphic images, and its usage as well. All the steps are 
closely connected with each other. Conveying the meaning of new lexical items should always go along with two other elements of the first stage.

\subsubsection{Semantization}

Conveying the meaning of a new lexical unit, semantization, associates it with the notions known to the learner from his/her mother tongue. Traditionally, ways of semantization are differentiated into those using translation into mother tongue, and the ones which do not use it. Non-translation ways of semantization include use of visual methods and use of language.

Use of visual methods is demonstrating objects, pictures, movements, etc. This method gives an opportunity to create direct association between an object and a foreign word without the help of mother tongue. Visual presentation can be widely used in Aviation English when a lexical unit means a particular object, though its application is impossible when teaching lexis with abstract meaning.

The examples of using visual methods as a non-translation way of vocabulary semantization in Aviation English course may be the following:

1. Showing objects for demonstrating flight instruments, black boxes, rudder, etc.

2. Showing pictures for demonstrating parts of aircraft (e.g. wings, fuselage, cockpit etc. See Fig. 2)

3. Showing videos for demonstrating phases of flight (e.g. take-off, approach, cruising, landing, fuelling, etc.).

Semantization with the help of language can be provided by means of the context or an illustrative sentence and is characterized by language guess. Being based on knowing facts and understanding general meaning of the sentence, it is naturally applied in Aviation English classes. E.g. All the 189 passengers were in the cabin and the plane was ready for take-off.

Another way of semantization with the help is comparing a new lexical unit with other words already known in the target language. It helps understand the meaning of a new unit on the basis of the other one learnt earlier due to their common feature (synonym) or contrasting one (antonym). Paraphrasing and contrasting are here the possible strategies used by the teacher to encourage students' understanding. E.g. steering wheel - rudder, undercarriage-landing gear (synonyms), climb-descent, slow down expedite (antonyms).

Giving definition is conveying the meaning of a word by means of other words that are already known to students. Definition must be clear and distinct, using mostly simple words. That requires students to be properly trained and have enough background knowledge. E.g. control tower - a tall building at an airport from which the movements of air traffic are controlled; to taxi - to move slowly along the ground before take-off or after landing; threshold - the beginning of an airport runway on which an aircraft is attempting to land.

Special attention when conveying the meaning of vocabulary items must be given to those which may get students into confusion due to some differences in their meaning in English and in students' mother tongue. For example, English 'first officer' meaning 'the second in command to the captain on an aircraft' is translated into Russian like 'второй пилот (vtoroy pilot)' where the word 'второй' literally means 'second' (not first). In this case usage of students' native language seems quite reasonable (but of course, it should 
be used after attempts to explain the meaning using non-translation ways of semantization) and is justified only because it is important to make sure that students understand the meaning correctly.

We stress that none of the ways of semantization is universal and multipurpose. When choosing the way, the teacher should take into consideration different factors: qualitative features of a lexical unit, whether it refers to active or passive vocabulary, students' level of knowledge, etc. In many cases it is desirable to combine two or more ways, most often by using visual methods together with context or illustrative sentences. It is the teacher who decides which presentation strategy would work better in that educational context.

\subsubsection{Addressing the word form}

Apart from getting acquainted with semantics of a new lexical unit during the first stage of presentation, students should also be involved in work on its sound and graphic images, as well as usage. As for the sound image of a new word, teachers may pronounce the words themselves, but should rather actively use recordings where students can hear native speakers (Peace Corps volunteers help teachers provide such recordings at our Academy) or non-native speakers from other cultures. Students can do phonetic drills and try to improve their pronunciation. The teacher should stress the vital importance of pronunciation in aviation communication, since it is conducted in verbal manner without any eye contact between a pilot and air traffic controller and often involves specialists of different nationalities.

When presenting the sound form of the word, particular attention in Aviation English needs to be paid to transcription (i.e. a graphic form of the sound image), stress (primary and secondary stress, stress shift in conversion noun-verb), word origin if having any peculiarities of pronunciation, e.g. French words in Aviation English. Let's turn to some examples.

Fuselage - a word of a French origin, having sound /3/ not characteristic of native English words. Thus, transcription and the oral form of pronunciation are presented. Stress is on the first syllable here, unlike with its French original.

The words disembark |,disım'ba:rk|, push-back |'pof,bæk|, decompression |,di:kəm'pre $\int \mathrm{n} \mid$, airworthiness |'eə,w3:ðinəs|, pullout |'pol, aut| and many other words in aviation English have a secondary stress which is absent in a variety of other languages (e.g. Russian) that is why special attention is needed while presenting the sound form of lexical units.

Besides, taking into account the notion of conversion in the English language and frequent stress shift in such cases (which is crucial for distinguishing meaning in a flow of speech) a teacher should underline the importance of correct stress placement, e.g. in words transfer, increase, decrease, etc.

Particular attention should be paid to the lexical items which have quite similar sounding in the English language and the students' native language, but completely different meaning, especially in aviation English. E.g. the word cabin is similar to the Russian word кабина (kabina), however in Russian it is used in the collocation кабина пилота, that is having the meaning 'pilot's working place, cockpit', and in English it means quite a different part of the aircraft, namely the passenger area of an airplane.

All the new lexical units are to be presented graphically during presentation stage. It helps students form their graphic image for further usage during their professional 
activity (Pilots, air-traffic controllers and other aviation staff use not only oral communication with each other, but have to compile reports in written form as well). When presenting a graphic form there are also some points which need special consideration, e.g., discrepancy between spelling and pronunciation. To illustrate: levera word, meaning a projecting arm or handle that is moved to operate a mechanism (e.g.'a control lever'), pronounced /'li:va/ - is an example of a quite often phenomenon in English when the graphic form of a word does not coincide with the sound one (which should be additionally underlined by the teacher for students to avoid mistakes). The same discrepancy between spelling and pronunciation is observed in Aviation English in aisle, threshold, vehicle, wounded, etc.

\subsubsection{Working on the word usage/collocation}

Word usage is about the register, the context in which a lexical item tends to be used. Taking into account that aviation is a regulated professional sphere, we can state that there are certain conditions for each word to be applied in. Thus, for example, a phrase Words twice is used to convey the meaning Please send every word or group of words twice and is used in the situation when communication is difficult due to some problems. Therefore, every word or group of words in this message will be sent twice to ensure correct understanding. So, presenting the phrase to students a teacher surely explains not only the meaning, but also the context it occurs in. Correction in radiotelephony is used when ATC has given the invalid information or has made an error and wants to change it for another one, e.g. Air China 102 cleared to Beijing via Bekol, flight planned route, maintain 7000 feet, Bekol Two Charlie, correction Bekol One Alpha Departure, request level change en route for 10200 metres, squawk 5325. The same description of the context can be presented for most lexical items in pilot-air traffic controller communication as each flight stage or any standard and emergency situation tends to have a certain set of vocabulary items used to convey the necessary information required for that phase. While establishing communication read, radio check, adjust transmitter, short count, are of high occurrence, as well as commence push-back, set brakes, disconnect, at the start-up stage of flight.

Moreover, usage is not only the context, but the way how the word is related to others, i.e. synonyms, antonyms, lexical sets. Since Aviation English, especially radiotelephony communication, tends to limit synonyms or very clearly differentiate them by the context and semantics in order to avoid misunderstanding, presenting synonyms is quite a rare phenomenon. If such occurs, main attention should be devoted to differences in meaning and situations of using these words. Thus, clear and approve both mean allowance, but the former one is used before the departure to give short instructions as for the future flight (e.g. CCA 102 cleared to Beijing via Bekol, flight planned route, initial climb to 9000 feet, Bekol 2C Departure, request level change for 10200 metres en route squawk 5310), while the latter is applied to allow frequency change, start-up, push-back, tow, etc. (e.g. CCA 101 pushback and start-up approved, expect runway 36L, D08 Departure, squawk 3123). However, other types of aviation communication, different from pilot-air traffic controller communication, do not have such strict limits and sometimes allow synonymous expressions. Students may get acquainted with such synonymous series as landing gear - undercarriage, cargofreight, apron - ramp, steward - flight attendant, cockpit - flight deck, etc. Antonymous 
chains are of frequent occurrence as flight process is characterized by opposing actions, such as climb - descend, expedite - slow down, etc. and they need to be presented to students.

When presenting new vocabulary in word combinations and sentences, appropriate attention needs to be paid to explaining words ability to be used with other parts of speech, i.e. collocation; teachers should constantly encourage students to provide examples, involve them into active cooperation at this stage. Collocations are an essential part of lexical knowledge important for fluent speech and writing and refer to the way how two or more words are typically used together. For example, we talk about heavy rain but not heavy sun, or in aviation we say Pass your message not Transmit your message. The most frequent collocations in Aviation English are verb + noun (report altitude, request descent, extend downwind), adjective + noun (flight level, immediate departure, initial climb), verb + adverb (continue visually, turn left). For example, when presenting the word to taxi in Aviation English the following collocations can be mentioned: taxi with caution, taxi to the apron, taxi ahead.

We want to underline that conveying the meaning of a new lexical unit, presenting its graphic and sound images, as well as explaining collocations take place almost simultaneously, are closely interconnected and cannot be separated from each other. This is especially evident when using non-translation ways of semantization where new vocabulary is used either in context or in comparison with other lexical units which are already familiar to students. In this case students guess the meaning of new lexical items, get their sound image as well as graphic form (all the new words and phrases are to be presented graphically either on the blackboard or by visual and technical means, such as pictures, computers, interactive whiteboards, etc.), learn about their collocation at the same time. Of course, students go through these steps subconsciously, not even focusing on distinguishing one process from another.

The stage of presentation smoothly turns into the next step of multiple exposures.

\subsection{Providing multiple exposures}

Having presented the new vocabulary to students, the teacher should aim at encouraging them to practice, i.e. to provide multiple exposures and try to develop students' subconscious (opposed to controlled processes) word recognition and production. Every time a student encounters a word in context, he/she makes a step toward fully mastering it in terms of meaning, form, collocation and usage. First, students are involved into activities that focus on mastering skills that will allow them to automatically use the chosen word in phrases and sentence. Second phase of this learning process reaches the next level - fluent use of a certain word on out-of-phrase level, dialogues or monologues in particular.

To develop fluency in phrases and sentences, we offer a wide range of activities with the initial focus on memorizing and practicing collocation(s) of a particular word. Exercises used for that can be as follows: 
E.g. 1. Match a line in $\mathbf{A}$ with a line in $\mathbf{B}$ :

\begin{tabular}{|l|l|}
\hline $\boldsymbol{A}$ & $\boldsymbol{B}$ \\
\hline snow & density \\
\hline boarding & airspace \\
\hline air traffic & tanker \\
\hline shuttle & plough \\
\hline fuel & of air traffic \\
\hline to prevent & pass \\
\hline controlled & safety \\
\hline aviation & collision \\
\hline flow & bus \\
\hline
\end{tabular}

E.g. 2. Fill in the gaps with the words form the box:

Prevent, weather, activity, communication, airspace, emergency, area, provide, flows, multi-engine, radar,

... plane, .... controllability in the flight, surveillance ..., thunderstorm..., the use of ..., air traffic.... collision, in case of ..., landing..., ...conditions, establish ....

Exercises aimed at guessing and/or matching the given words with their definitions and the following use of these words in different aviation contexts are often practiced together (See examples 3, 4 below). It is important to provide students with continuous workflow in which stages of semantization and multiple exposures go hand in hand with each other, thus, making learning vocabulary more productive and smooth.

E.g. 3. Match the terms in column A with their definitions in column B:

\begin{tabular}{|l|l|}
\hline $\boldsymbol{A}$ & $\boldsymbol{B}$ \\
\hline 1. fuselage & a. items on board the aircraft that are not structural or \\
2. equipment & part of any system \\
3. collision & b. the hull or central body of an aircraft complete with \\
4. deviate & ribs, stringers and skin \\
5. airprox & c. To do something different to what is expected \\
& d. When something crashes into something \\
& e. The name for a' near miss' in aviation \\
\hline
\end{tabular}

E.g. 4. Complete the sentences with the words in column A from the previous exercise:

1. The accommodates the passengers, payload and crew.

$2 . \quad$ ranges from passenger seats and safety items to cargo nets.

3. Whether IFR or VFR constant vigilance is necessary to stop a(n) leading to $a(n)$

4. Inform ATC if you are forced to from your course 
The next step includes practical exercises on the vocabulary already learned, but now included in sentences. These can be unscrambling sentences, defining whether the sentence is true or false, finding discrepancies in the message conveyed in a sentence. The example is presented below in exercise 5.

E.g. 5. Unjumble the words in 1-5 to form common transmissions related to start-up and push-back:

1. Start / Eastern58 / 21 / request / Bay / up

2. Start / Eastern $58 /$ approved / up

3. 23 / up / at / start / time / Eastern 58

4. Eastern 58 / once / clear / the 747 / pushback / wilco / to / is cleared

5. 5 C23 / inbound / minutes / expect / delay / 5 / traffic / for / due / Eastern 58

As for exercises used for developing fluency on out-of-phrase level (dialogues or monologues), below we demonstrate some examples.

E.g. 6. Select the most appropriate answer out of the three choices:

Pilot: Beijing Tower CSN 301 (1) Hong Kong request

(2) information.

Controller: CSN 301 Beijing Tower, (3) wind $250^{\circ} \quad 8 \mathrm{~m} / \mathrm{s}$ Pilot: Runway 21, (4) $15 \mathrm{~m} / \mathrm{s}$ temperature 25 dew point 18 (5) 998 .

1. a) destination b) gate c) fly

2. a) take off b) departure c) traffic

3. a) departure $R W 21$ b) take off and landing $R W 21$ c) holding $R W 21$

4. a) changing to b) going to c) gusting to

5. a) $Q F E$ b)QNH c) altimeter

6. a) QNH 998 out b) altimeter 998301 c) QFE 998 CSN 301

The exercise above is aimed at training fluency on the level of dialogues and encourages students to choose proper words to complete pilot's and ATC's phrases. Quite similar exercises can be used for monologues when students are instructed to fill in the gaps either by having a selection of words for each gap or by none of the words given. Such exercises may present monologues with weather reporting service or a pilot's report on some emergencies that took place during the flight.

E.g. 7. Fill in the gaps in the ATIS transmission with the suitable words. Then check your answers with the recording:

This is Hong Kong International Airport Tango at time 09 00, runway-inuse 13, expect IGS Surface wind 090 10-20 knots 9 kilometres, cloud scattered 1400 feet, scattered 1800 feet, _- 24 , $1011 \mathrm{hPa}$. Expect wind shear and moderate turbulence on approach and 
departure. Acknowledge Tango on frequencies 119.1 for arrival and 124.65 for departure.

\subsection{Active involvement in different speech acts}

On the last stage of teaching aviation vocabulary, i.e. active involvement in different kinds of speech acts, we offer several types of practical tasks to be used for developing skills of dialogue speech. Making up conversations in pairs according to the instructions which describe a situation during flight, either a routine one or an emergency, roleplaying are ways of encouraging students to use vocabulary.

E.g. 10. Work with a partner. Student A is a pilot of N340S, a light aircraft, maintaining 5,000ft, VFR. Student B is an ATC. Read the dialogue outline and decide what to say:

\section{ATC}

N340S

Advise AC of WX $20 \mathrm{~nm}$ ahead Say severe $C B$ s

Say other AC re-routing to the north Give WX information

\section{Ask about weather}

Ask if anyone has flown through the area Ask for WX to the north Request heading to follow deviating traffic

Role play the dialogue, then change roles and do it again.

Of course, at initial stages, students should be instructed to make up short dialogues (e.g. asking request for some actions and getting back the replies); further on, with acquiring more knowledge on a subject and building up their vocabulary, dialogues should become longer and more complicated. Debriefing which usually takes place after a flight is a nice choice for training role playing. It is an excellent practice drill because students use not only standard phraseology which is basic in conversations between pilot and ATC during routine situations, but have an opportunity to train the language in full, especially if the instructions are about some emergencies during the flight.

Another exercise for developing skills of using vocabulary in dialogues can be a discussion, regarding some situations during the flight, pilot's or ATC's actions, development of aviation industry, etc. Such activities give an opportunity to practice not only a conversation of two people, but to have a polylogue.

Here are examples of questions that can be discussed:

1. What things do ATCs consider when managing departing traffic?

2. What problems are associated with incorrect weight and balance?

3. What procedures do you have to follow if you have an in-flight bomb threat at work?

4. What is your opinion of current security measures?

5. How has security changed in the last 20 years?

6. What changes in security do you expect in the future?

Sometimes, visual aids are used in practicing routine. For example, a video or a tape are demonstrated to students with following discussion on what they have seen or heard. As for monologues, students are asked to make reports on flights both verbally and in written form, describe pictures and videos representing different emergencies or 
comment on pilot's actions in a particular situation. All these exercises help students practice their vocabulary usage in speech without prior preparation and get ready for carrying out their professional duties in real life.

\section{CONCLUSION}

This article on methodology studied methods for teaching Aviation English vocabulary to students. Despite distinctive characteristics, teaching aviation vocabulary may follow the same logical procedure as teaching plain English lexis. Given the basic challenges and general logic of vocabulary teaching process, aviation vocabulary teaching stages have been defined. Each stage has been described in detail considering the peculiarities of the aviation register; examples of the most frequent or specific cases, presenting model exercises have been shown.

The techniques and exercises we have described in this article give an idea on how teaching aviation vocabulary can be organized in educational institutions. This topic is of great importance due to ICAO requirements, as well as due to the small number of available lexical exercises in Aviation English textbooks. Authors of this article hope that other teachers can use this methodological paper as a basis for their work and will find it inspiring in terms of creativity in teaching process, which can produce a stunning outcome.

\section{REFERENCES}

Akbarov, A.A. (2010). Pedagogical Implications of Lexical-Based Language Analysis In Rata, G. (Ed.) Teaching Foreign Languages: Languages for Special Purposes (pp. 174-180). Newcastle upon Tyne: Cambridge Scholars Publishing.

Bieswanger, M. (2016). Aviation English: Two distinct specialized registers? In Schubert, Ch., Sanchez-Stockhammer, Ch. (Eds.), Variational Text Lingusitics: Revising register in English (pp. 67-85). Berlin/Boston: Walter de Gryuter GmbH

Chuksina, O. V. \& Yanovskaya, H. S. (2014). Metodicheskiye usloviia obucheniia professionalnoy aviatsionnoy terminologicheskoy leksike (Methodological conditions to teach professional aviation terminology). Trudy MAI, 72. Retrieved from https:// www.mai.ru/upload/iblock/2eb/2eb76c7451fe7494a6ecf9ad7bc04801.pdf

Dudley-Evans, T. \& St. John, M. J. (1998). Developments in ESP: A Multi-Disciplinary Approach. Edinburgh: Cambridge University Press.

Hatch, E., \& Brown, C. (1995). Vocabulary, Semantics, and Language Education. New York: Cambridge University Press.

Hutchinson, T., \& Waters, A. (1987). English for specific purposes: a Learningcentered Approach. Cambridge: Cambridge. University Press.

ICAO (2010). Manual on the Implementaion of ICAO Language Proficiency Requirements. Doc 9835 AN 453, $2^{\text {nd }}$ ed. Montreal, Canada. Retrieved from https://www4.icao.int/aelts/ uploads/icao\%20doc9835\%202nd\%20edition.pdf

Kolosov, V. A. \& Ivanova, T.A. (2000). Analiz oshibok rechevoho vzaimodeistviia ekipazhey i dispetcherov UVD (Analysis of mistakes in speech communication between crew and air traffic controllers). In Psihophiziolohicheskiie problemy povysheniia rabotosposobnosti liotnoho I dispetcherskoho sostava hrazhdanskoy 
aviatsii (Psychological and physiological problems of improving efficiency of civil aviation crew and ATCs) (pp. 90-101).Saint Petersburg: Civil Aviation Academy.

Nation, I.S.P. (2001) Learning vocabulary in another language. Cambridge: Cambridge University Press.

Seal, B. D.(1991). Vocabulary learning and teaching In Celce-Murcia, M. (Ed.) Teaching English as a Second or Foreign Language (pp. 296-311). Boston, MA: Heinle \& Heinle.

Secer, Y. E. \& Sahin, M. (2014). Challenges of Teaching Aviation Vocabulary and Radio Phraseology at High School Level. International Journal on New Trends in Education and Their Implications, 5 (4), p.110-120.

Smeliakova, L. P. \& Skliarenko, N. K. (1999). Protses zasvoiennia leksychnogo materialy (Process of acquiring vocabulary) In Nikolaieva, S. Yu. (Eds), Metodyka vykladannia inozemnyh mov u serednikh navchalnykh zakladakh (Methodology to teach foreign languages at secondary schools) (pp. 93-103). Kyyiv: Lenvit.

Strevens, P. (1988). ESP After Twenty Years: A Re-appraisal in Tickoo M. ESP: State of the Art (pp.1-13). Singapore: SEAMEO Regional Centre.

Takač, V. P. (2008). Vocabulary Learning Strategies and Foreign Language Acqusition. Clevedon: Multilingual Matters.

Wang, A. (2011). A Methodological Probe to Aeronautical English Vocabulary Instruction.Open Journal of Modern Linguistics. Vol. 1. No. 2, p.45-51. 